\title{
A atenção em $A$ preparação do ator de Stanislávski
}

\section{Resumo}

O presente artigo visa discutir a influência da atenção, proposta como conceito pela psicologia, no início do século XX, na obra A Preparação do Ator de Stanislávski. Tal empreitada é feita a partir de uma minuciosa revisão da obra, após a qual, propõe-se uma reordenação na sequência do treinamento, proposto no livro pelo Diretor russo.

Palavras-Chave: Stanislávski; Ator; Atenção

\section{Attention in Stanislávski's An actor prepares}

\section{Abstract}

This article aims to discuss the influence of the attention, proposed as a concept by the Psychology, in the early twentieth century, into the Stanislávski's An actor prepares. Such task is achieved from a review of this book, after which is suggested a reorganization of the training sequence proposed, in the book written by the Russian director.

Keywords: Stanislávski; Actor; Attention

Constantin Stanislávski é sem dúvida um dos mais influentes pensadores teatrais do século XX. Seu "método" de preparação de atores e criação de personagens representou uma verdadeira revolução no fazer teatral ocidental - revolução que já era apontada como necessária por Diderot (2005) e posteriormente por Craig (2004), ao dizer que o teatro poderia alcançar novos patamares com a sistematização do trabalho do ator.

O esforço de Stanislávski empregado na construção de um teatro que fosse eficiente em sua comunicação com o espectador teve como mais expressivas as encenações das peças de Anton Tchékhov desenvolvidas junto ao Teatro de Arte de Moscou. Esta experiência originou diversas teorias, sendo que algumas compartilham e verticalizam as ideias de Stanislávski, ao passo que outras trabalham na negação da mesma.

Apesar de negar as suas pretensões científicas na introdução de El trabajo Del actor sobre si mismo (2010)르. Stanislávski não tem como negar a influência que o pensa-

\footnotetext{
1 Ator, diretor, e doutorando em artes cênicas pelo PPGAC da USP sob a orientação da Prof $^{\mathrm{a}}$ Dr $^{\mathrm{a}}$ Sílvia Fernandes. É Graduado em Artes Cênicas pela UNICAMP e mestre em Artes Cênicas pela USP.

${ }^{2}$ Utiliza-se como base deste estudo a tradução espanhola da obra feita por Jorge Saura a partir do original Russo.
} 
mento científico exercia naquele momento sobre o seu método. Como nos aponta Jorge Saura, em suas notas à edição espanhola, ele conhecia e utilizava diversos termos da biologia e da psicologia para estruturar seu pensamento e de certa forma validá-lo.

Em numerosas ocasiões Stanislávski cita em seus escritos obras de médicos, psicólogos e biólogos, hoje já esquecidos, como forma de validar cientificamente suas descobertas e deduções empíricas. A falta de interesse da ciência para com o teatro, expressada em diversas ocasiões pelo diretor russo, manifestava seu temor que as suas teorias sobre a arte do ator pudessem não ser levadas a sério. Deve-se ter em vista que quando Stanislávski escreve seu livro (por volta de 1935) havia apenas quarenta anos que a profissão do ator tinha deixado de ser considerada, na Rússia, própria de pessoas incultas e de índole duvidosa. (STANISLÁVSKI, 2010, P. 25).

Por outro lado, acredita-se que o surgimento do pensamento científico no teatro, que tem como marco a produção bibliográfica de Stanislávski, provém de uma necessidade característica do fim do século XIX, de revisar todos os conhecimentos humanos a partir do olhar da ciência. Como aponta Crary (2001), este período foi marcado pela relativização da objetividade do conhecimento empírico; a partir deste período o mundo ocidental passa a atribuir certa parcialidade ao olhar humano.

O científico em Stanislávski está pautado, principalmente, no diálogo que sua obra estabelece com os conceitos colocados em pauta pela nova ciência da psicologia (como os do subconsciente, da atenção, da imaginação e da memória), principalmente, no estabelecimento das bases de um método (científico) de criação cênica. Do legado escrito deixado pelo encenador russo, este trabalho concentra-se sobre seus apontamentos acerca da preparação do ator (Stanislávski, 2010).

Ao analisar o livro de Stanislávski e os treinamentos que temos em escolas e universidades de teatro no Brasil, constata-se o quanto seus escritos foram fundamentais para o desenvolvimento de um modelo para a preparação do ator, que hoje é predominante, tanto no ensino técnico quanto no ensino universitário. Tendo esse fato em vista é necessário levantar uma questão: qual versão de Stanislávski é ensinada aos alunos brasileiros? Quando se faz uma leitura atenta da obra em suas versões traduzidas diretamente do russo (neste caso as edições espanhola e italiana) em comparação com a versão traduzida da obra americana, percebe-se que a versão

Esta tradução foi colocada em comparação com as traduções brasileira e italiana e mostrou-se a mais completa e confiável, uma vez que não foi possível o acesso ao texto original em Russo. 
americana impera no Brasil, uma vez que a tradução de Pontes de Paula Lima, feita a partir da tradução americana, é a única disponível no Brasil, em língua portuguesa.

Deseja-se não meramente supor que há uma leitura correta do "método", mas relativizar a visão que se tem do livro como uma obra fechada e sagrada. Há na obra estudada uma série de aberturas, decorrentes em especial da tendenciosa tradução americana, que permitem, ainda hoje, que diversas leituras sejam feitas, atualizando o pensamento do autor diante do mundo contemporâneo. Seria impossível, em um artigo, destrinchar a obra ponto a ponto, comparando as versões russa e americana e este é um dos motivos (dentre os muitos) que faz com que este estudo se concentre na questão da atenção.

Mas por que a atenção? Pode haver diversas respostas a esta pergunta. Pode-se dizer que dentre os fundamentos principais do treinamento, como nos aponta Farber (2008), a atenção é, nos dias de hoje, o primeiro tópico do ensino de teatro nas principais escolas Russas, como a SPAGATI (Academia Estadual de Teatro de São Petersburgo) e a RATI-GITIS (Academia Russa de Teatro). Estas escolas abordam a atenção no sentido de desenvolvê-la, para que no palco e na vida o ator possua uma maior capacidade de concentração, criação e ação. Ainda pode-se dizer, tal como um dos principais psicólogos do início do século XX, Hugo Munsterberg, que a atenção é a primeira e a principal função interna que cria o significado do mundo externo para nós. Tudo que percebemos é controlado pela relação entre a atenção e a desatenção. (MUNSTERBERG, 2004, p.31)

O livro El trabajo del actor sobre si mismo (2010), que contém a base do método de preparação do ator para Stanislávski, é organizado em forma de um suposto diário de trabalho do aluno Kóstia, um iniciante no estudo da arte teatral que está sob a tutela do diretor Tórtsov. Por ser escrito na forma de um diário, é possível dizer que a obra em questão apresenta uma relação direta entre o treinamento e o tempo, ou seja, a proposta de Tortsóv (personagem da obra que representa a voz do autor) desenvolve um conteúdo ordenado dos conhecimentos mais básicos para os mais avançados, em uma linha temporal contínua.

Para analisar o treinamento proposto por Stanislávski, no aspecto relativo à ordenação de seus conteúdos, temos duas possibilidades: ao seguir a ordem aparente de seu livro pode-se dizer que a preparação técnica do ator, para possibilitar que sejam feitas as primeiras cenas, passa sequencialmente por exercícios de 1.ação, 2.imagi- 
nação, 3.atenção e 4.relaxamento; Mas ao olhar, num segundo momento, parece que esta ordem deriva de um "erro" do diretor Tórtsov na condução do treinamento deve-se levar em consideração que o livro está escrito na forma de um romance e não de um manual - ou seja, a ordem efetivamente proposta pelo "método" é diferente da ordem aparente e seria composta por um treinamento que possui a seguinte ordem cronológica 1.atenção, 2.imaginação, 3.ação e 4.relaxamento.

Portanto, quando depois de passar por exercícios de imaginação (no capítulo 5), Tórtsov percebe que sem a atenção não é possível nem à ação, nem à imaginação desenvolverem-se plenamente, ele demonstra que a atenção seria verdadeiramente o primeiro passo para o treinamento técnico do ator que estivesse disposto a seguir seu método.

Ao reconhecer a atenção como elemento primordial do treinamento do ator, Stanislávski introduz no teatro uma descoberta que havia sido feita por psicólogos como Helmoltz ${ }^{3}$ e Munsterberg ${ }^{4}$ no início do século $\mathrm{XX}$ : que todo o mundo cognitivo deve passar pela atenção para poder ganhar o nível do consciente. Diante disso, torna-se necessário ao ator uma atenção diferenciada do não-ator. Para explicitar melhor o que seria a atenção no teatro, o diretor Tórtsov formula uma explicação que parece copiada de um livro de Hugo Munsterberg, ou de algum outro psicólogo de seu tempo:

\footnotetext{
Quanto mais chamativo for o objeto, mais atrairá a atenção. Não há um só momento na vida de um homem em que sua atenção não se sinta atraída por algum objeto. E quanto mais interessante for o objeto, maior será seu poder sobre a atenção do artista. Para distraí-lo da plateia, deve-se introduzir habilmente um objeto interessante aqui, no palco, como a mãe distrai a criança com um brinquedo. (STANISLÁVSKI, 2010, p.104)
}

Neste trecho demarca-se ao mesmo tempo sua visão de como a atenção do ator age, bem como a postura que o diretor deve ter diante disto. Para Stanislávski o principal problema que seu sistema busca abordar, no que se refere a atenção, é relativo ao ator que deixa de se concentrar em sua personagem e no palco para concentrar-se na plateia, no crítico, no diretor etc. Para reforçar a suposta ligação entre o método de trabalho de Stanislávski e a pesquisa da psicologia do início do século XX, transcreve-se abaixo um trecho do livro no qual Hugo Munsterberg analisa a atenção no evento teatral:

O foco da atenção é dado pelas coisas que percebemos. Tudo o que é barulhento, brilhante e incomum atrai a atenção involuntária. Devemos voltar nossa mente (atenção) para o lugar onde ocorre uma explosão, temos que

\footnotetext{
${ }^{3}$ Médico, filósofo e psicólogo alemão que foi um dos precursores dos estudos sobre a atenção.

${ }^{4}$ Psicólogo alemão e professor na Universidade Harvard. Foi quem desenvolveu primeira teoria sobre o filme ao aplicar seus conhecimentos sobre os processos mentais superiores sobre a temática da recepção da cena (teatral e fílmica).
} 
ler o anúncio luminoso que pisca. Certamente, o poder de motivação das percepções impostas à atenção involuntária pode ter origem em nossas reações. Tudo o que mexe com nossos instintos naturais, tudo o que provoca esperança, medo, entusiasmo, indignação, ou qualquer outra emoção forte assume o controle da atenção. [...] Seguramente, não faltam meios de canalizar a atenção involuntária para pontos importantes no teatro. Para começar, o ator que fala prende nossa atenção com mais força do que os que estão calados naquele momento. [...] O ator que vai até o proscênio está imediatamente no primeiro plano de nossa consciência. Aquele que levanta o braço enquanto os outros estão parados ganha a atenção para si. Sobretudo, cada gesto, cada personagem organiza e ritma à multiplicidade de impressões organizando-as em benefício da mente. A ação rápida, a ação incomum, a ação repetida, a ação inesperada, a ação de forte impacto exterior vai forçar nossa mente perturbando o equilíbrio mental. (MUNSTERBERG, 2004, P. 32- 33)

Diante do discurso de Munsterberg que expressava, de certa forma, uma continuidade do discurso de William James ${ }^{5}$, Théodule Ribot ${ }^{6}$, Wilhelm Wundt ${ }^{7}$ e outros psicólogos do início do século XX, percebem-se diversas aproximações ao vocabulário utilizado por Stanislávski. Evidencia-se o conhecimento do encenador russo da pauta de discussão da psicologia. Não se pode deixar de reparar na carga teórica e conceitual que recai sobre termos que ele utiliza, tais como: subconsciente e atenção dirigida. Ainda que num processo de treinamento pudesse haver uma referência à atenção enquanto uma metáfora de trabalho, a ideia de uma atenção dirigida ou focalizada está diretamente ligada aos conceitos desenvolvidos pela psicologia de seu tempo.

É um vestígio dessa influência a afirmação de Stanislávski de que a atenção dirigida a um objeto desperta ainda mais a observação do ator. Deste modo a ação entrelaçada com a atenção cria um forte vínculo com o objeto. (STANISLÁVSKI, 2010, p.105). A partir desta afirmativa pode-se concluir que a atenção e a ação estão entrelaçadas de modo definitivo no momento da apresentação tal como iria figurar na prática de Stanislávski, anos mais tarde.

Deduz-se de seus escritos, que a atenção do ator durante o treinamento é diferente da utilizada ao longo da apresentação. No momento do treinamento é necessário que a atenção voluntária do ator seja treinada separadamente da ação e da imaginação conforme acompanha-se pela própria organização de seu livro. Já no momento da apre-

\footnotetext{
${ }^{5}$ Psicólogo e filósofo estadunidense considerado o pai da psicologia moderna. Foi um dos principais mentores de Hugo Munsterberg, sendo o responsável por trazê-lo para Harvard.

${ }^{6}$ Psicólogo Francês que influenciou diretamente as teorias de Stanislávski sobre o ator. Destaca-se a influência de seu livro "A Psicologia da Atenção" (de 1889), o primeiro dedicado exclusivamente ao assunto, do qual Stanislávski empresta diversos termos empregados em sua obra.

${ }^{7}$ Psicólogo, médico e filósofo alemão. É um dos pioneiros da psicologia experimental, tendo fundado o primeiro laboratório de psicologia do mundo.
} 
sentação, durante a qual a atenção do ator está em sua maior parte dominada pela força do hábito, ela deve integrar-se de forma definitiva à ação e à imaginação. Como aponta Jorge Saura em suas notas sobre o livro El trabajo del actor sobre si mismo,

Com esta intervenção de Tórtsov [sobre a condução da atenção do ator], Stanislávski salienta a natureza ativa da atenção cênica, ideia que ganhou força na prática pedagógica de seus últimos anos e que foi desenvolvida por seus discípulos. Se no princípio os exercícios sobre esta área tendiam a fixar a atenção sobre um objeto durante um tempo mais ou menos prolongado ou a ampliar e reduzir os círculos de atenção, com o passar do tempo a atenção se converteu em parte integrante da ação, ao emanar da ação. (SAURA Apud STANISLÁVSKI 2010, p.105)

A afirmativa de Saura reforça nossa proposição de uma leitura da atenção e da ação como elementos indissociáveis no processo de criação e de atuação para o encenador russo. Sem dúvida, a principal estrutura para entender a atenção no treinamento proposto pelo "sistema" de Stanislávski é a dos círculos de atenção.

Para compreender a proposta dos círculos de atenção nos voltamos por um instante para a teoria do holofote descrita por Cristian Wolf8 em 1740, segundo a qual a atenção visual se comporta tal como um foco de luz de um holofote: quanto mais área ela abrange, mais rarefeita é sua luz e mais geral; por outro lado, quanto menor o foco, mais concentrada será sua luz, permitindo o detalhamento. A teoria de Wolf parece conter a explicação básica do modo como Stanislávski utiliza a palavra atenção em seu trabalho, a partir da relação espaço/detalhamento da percepção.

Para Stanislávski (2010, p. 111) o círculo de atenção já não se trata de um só ponto [de atenção], mas de todo um setor de pequena extensão que compreende muitos objetos independentes. Ele propõe que o círculo de atenção pode ser subdividido em três partes, segundo sua área de abrangência.

O pequeno círculo consiste em uma focalização (que pode ser feita através de uma luz ou do olhar focalizado) de um pequeno espaço fora de seu corpo, do qual seu corpo é geralmente o centro. Este é o circulo da solidão, pois quando não se vê o espectador, tem-se a sensação de que se está só em seu próprio quarto. O círculo médio é uma focalização em uma área bem ampla, onde não se pode atentar para todas as coisas ao mesmo tempo. O olhar tem que percorrer o espaço em busca de identificar sua delimitação. A grande área iluminada pelo foco de luz (no caso do exercício que utilizava focos de luz) já traz a impressão de que não se está só. O círculo grande é o maior de todos.

\footnotetext{
${ }^{8}$ Um dos mais importantes filósofos alemães. Sua teoria dos holofotes foi precursora dos estudos psicológicos sobre a atenção visual.
} 
As suas dimensões dependem do alcance da vista. Portanto num local aberto como uma praia, esse círculo só teria como delimitação física o horizonte.

De que serve a repetição de exercícios para a atenção durante o treinamento do ator? Segundo Stanislávski (2010, pp.116-117) para que o ator possa ter um treinamento que aumente a eficácia de sua atenção durante a cena, não deixando que ele se distraia de seu objetivo. A proposição pode ser entendida mais claramente a partir da fábula hindu contada por Tórtsov sobre o marajá que escolhe para seu ministro aquele que não sendo distraído por nenhum estímulo externo seja capaz de dar a volta caminhando sobre a muralha da cidade com um copo de leite cheio até as bordas sem derrubar uma gota sequer. Para Stanislávski o bom ator é esse, capaz de concentrar-se em seus objetivos.

Convém ressaltar que esta conceituação de atenção utilizada por Stanislávski tem como referência a atenção visual, está em acordo com as pesquisas dos psicólogos do início do século XX. No entanto, a sua teoria se afasta da psicologia quando se refere ao objeto da atenção. Neste ponto Stanislávski deixa o rigor científico para abordar o tema de um modo prático e mais metafórico.

Quando ele propõe uma distinção dos objetos internos e externos, ao que parece, está se referindo ao efeito que a lembrança de uma experiência causa no ator e não diretamente a atenção sensorial. Diz que o objeto "externo" faz referência a uma lembrança, em geral associada à visão. Por outro lado ele considera que "objeto interno" é aquele relacionado a uma reação corporal efetiva, como salivar, que está mais ligada ao paladar, ao tato, ao olfato e à audição. Transcreve-se abaixo um trecho no qual o assunto é abordado de forma mais clara.

(Tórtsov diz) - Paulo, recorde o sabor do caviar.

- Já recordei - respondeu.

- Onde se encontra o objeto de sua atenção?

- Em princípio tive a imagem de um grande prato de caviar colocado sobre a mesa.

- Ou seja, que o objeto estava fora de você.

- Mas em seguida a visão me provocou sensações gustativas na boca e na língua - lembrou.

- Ou seja, dentro de você - observou Tórtsov-. Para aí também se dirigiu a sua atenção. Paulo, recorde agora da marcha fúnebre de Chopin. Onde está o objeto? 
- Em princípio fora de mim, no cortejo fúnebre. Mas os sons da orquestra soam em meus ouvidos, ou seja, dentro de mim mesmo - disse Paulo.

- Para onde se dirige a sua atenção, certo?

- Sim.

-Por consequência, na vida interna nós criamos no início representações visuais sobre a mesa do caviar ou sobre o cortejo fúnebre, mas depois através dessas representações despertamos as sensações interiores de algum dos cinco sentidos e fixamos definitivamente nesse lugar nossa atenção, que, portanto, converge em objeto de nossa vida imaginária, não por uma via direta, mas por via indireta, através do que podemos chamar de um objeto auxiliar. Isso é o que ocorre com nossos cinco sentidos. (STANISLÁVSKI, 2010, pp. 119-120)

Neste pequeno diálogo Tórtsov induz Paulo, com sua atenção voluntária, a pensar em objetos fora e dentro de seu corpo. A partir disso percebemos que, ao menos nessa obra, o autor está nos propondo exercícios justamente para fortalecer a atenção voluntária e impedir que a atenção involuntária desvie o ator de seu papel. Portanto a atenção do ator é, neste caso, sempre voluntária visando ao hábito através do treinamento.

Outra pista sobre a concepção de atenção para Stanislávski está em sua explicação de porque é possível para um equilibrista de circo fazer diversas coisas ao mesmo tempo: "A razão de ele poder realizar tudo isso ao mesmo tempo é que no homem a atenção tem múltiplos planos que não interferem um no outro.[...] Por sorte muito do habitual se torna automático. Com a atenção pode ocorrer o mesmo." (STANISLÁVSKI, 2010, p.125)

Pode-se dizer, a partir da análise dos escritos do autor, que numa situação teatral ideal, o ator deve agir prioritariamente a partir de sua atenção voluntária e do hábito por ela gerado, enquanto o espectador deve se utilizar principalmente de sua atenção involuntária para fruir o espetáculo.

Antes do início do treinamento técnico do ator, Stanislávski propõe que seja feito um diagnóstico da capacidade atentiva do ator e de seus hábitos através de uma prova de palco. Já no primeiro ensaio para esta prova de aptidão (como chamamos nos dias de hoje o teste para ingressar no curso de teatro) Stanislávski demonstra-nos a fragilidade da atenção pouco treinada nas palavras de Kóstia:

Assim que pisei no tablado, apareceu em minha frente a imensa boca de cena e por trás dela uma interminável penumbra. Pela primeira vez vi a partir do palco a plateia, agora vazia e deserta. Sentia-me totalmente desorientado. [...] Durante um longo tempo não pude me orientar no amplo espaço rodeado por cadeiras, nem concentrar minha atenção no que sucedia ao meu redor. (STANISLÁVSKI, 2010, p.21) 
A experiência na prova de palco serve de início para o treinamento prático, fornecendo ao diretor um diagnóstico da capacidade de concentração de cada aluno. Em seguida a esta prova ele demonstra, em vários trechos, a importância da atenção no treinamento do ator e como esta deve ser conduzida.

No início do capítulo 3, no qual se introduzem exercícios técnicos para o ator, ele desenvolve uma cena exemplar, na qual o personagem de Tórtsov fica sentado, imóvel, em uma cadeira. A ação de Tórtsov sentado na cadeira (STANISLÁVSKI, 2010, p.53) atrai de forma definitiva a atenção do aluno-espectador. Utilizando a focalização de sua atenção em cena, Tórtsov provocava reações, sensações e pensamentos em seu público, de acordo com seus objetivos.

A importância de um treinamento da atenção voluntária do ator para a realização de seus objetivos fica explícita também no exercício que Tórtsov propõe a Maria (STANISLÁVSKI, 2010, p.56-57). Ele pede que ela procure um broche no palco e sugere uma história (fictícia) como pano de fundo. No entanto, Maria se esquece do broche e fica "representando sentimentos", com a atenção voltada para os espectadores que a observam.

Neste ato narcisístico a atriz esquece o seu real objetivo em cena e, com isto, faz com que a cena perca sua eficácia no que diz respeito à comunicação com o espectador. Isto está ligado à concepção de Stanislávski sobre a qualidade da ação do ator. Para Tórtsov (e consequentemente para Stanislávski) a "boa ação" está ligada à eficácia do estímulo sobre a atenção do espectador, e por consequência ao afeto de sua memória, sua imaginação e sua emoção.

Sobre a importância da ligação entre atenção, ação, memória e imaginação para a geração de uma cena de qualidade, no capítulo 3 ele diz:

\footnotetext{
[em cena, Kóstia está fingindo que seus fósforos imaginários se apagam diversas vezes enquanto ele tenta acender a lareira. Tórtsov diz-lhe que este tipo de ação mecânica e sem fundamento acontecem, em cena, numa velocidade muito maior do que os atos conscientes e fundamentados e explica o porquê]

- Isso não é estranho - explicou -. Quando você atua mecanicamente, sem um fim determinado, não há nada que retenha sua atenção. Não leva muito tempo para mudar de lugar algumas cadeiras; mas se você quer organizá-las de um modo diferente, com um fim determinado, mesmo que apenas porque tem convidados e quer Ihes oferecer o assento segundo sua categoria, demorará um longo tempo para mudar de lugar essas mesmas cadeiras. (STANISLÁVSKI 2010, p.60-61)
}

Percebemos ao longo de sua obra, em especial no capítulo 10, no qual é tratado o tema da comunicação, que a finalidade do trabalho com a atenção do ator é maximizar a efetividade da relação que este estabelece com o espectador durante a apresen- 
tação, criando assim a possibilidade de se estabelecer uma comunicação efetiva entre o palco e a plateia. Como nos mostra Guerrieri, em sua introdução à edição italiana da obra, Stanislávski deixou apenas fragmentos de seus escritos sobre o espectador, mas não é por isso que ele é desconsiderado pelo seu método.

\begin{abstract}
A presença do público (o seu campo magnético como dizia Jouvet) produz, em um primeiro sentido, efeitos negativos sobre o ator: o hipnotiza, inibe sua fantasia, ou, ao contrário, faz com que ele se exiba, narcisismo este que interfere em sua atividade de intérprete e a desvia. Com uma série de exercícios que trabalham a presença e que reforçam a capacidade de concentração, de atenção, de 'solidão em público', combatendo a presença do público e reforçando a sua presença de ator, Stanislávski ensina, em primeiro lugar, a não se estar sob o domínio do público. [...] Faz parte desta concepção a estratégia de abordagem indireta no confronto com o espectador: o dever do ator é chegar ao público não por via direta, mas mediado pela personagem. Assim a comunicação se dá em níveis diversos como o visual, o sonoro, e também de subconsciente para subconsciente. E aí chegamos ao segundo ponto. O público é o pólo receptor da comunicação teatral, o cátodo do fluído da corrente cênica, e neste sentido integra e interpreta o evento cênico segundo certos processos mentais e estruturas fantásticas, que o ator deve conhecer e deve levar em conta. (GUERRIERI APUD STANISLÁVSKI, 2008, p.XXVII)
\end{abstract}

Diante desta afirmação de Guerrieri, propõe-se que enquanto os capítulos 3, 4, 5 e 6 (que falam sucessivamente sobre a ação, a imaginação, a atenção e o relaxamento muscular) estão preparando o ator para o encontro com o espectador, no sentido de torná-lo capaz de manter a sua própria atenção em seu objetivo, em sua ação, em sua imaginação e em seu corpo, os capítulos 10 e 11 (que versam, respectivamente, sobre a comunicação e a adaptação) abordam do ponto de vista do intérprete o momento da apresentação. Nestes capítulos mostra-se a importância do conhecimento do ator acerca dos mecanismos de recepção do espectador. Explicita-se como a atenção do ator deve agir neste momento para capturar e conduzir o espectador pela trama do espetáculo.

Esta ação de comunicação do ator, consigo mesmo e com seu companheiro, gera uma abertura sensorial e racional do espectador que vai captando involuntariamente as palavras e ações dos interpretes (STANISLÁVSKI, 2010, p. 252). Esta "captação involuntária" da qual Stanislávski fala pode ser compreendida como a ação da atenção involuntária do espectador agindo sobre a peça.

Portanto, o capítulo 10 trata, em resumo, de como o ator deve conhecer e estar sensibilizado à atenção do espectador. Postula que ao manter a atenção voltada para seu objetivo e, ao mesmo tempo, manter-se aberto para comunicar-se com as coisas e pessoas ao seu redor, durante a apresentação do espetáculo, o ator permite ao público um estado de prontidão e porosidade que libera sua atenção involuntária para agir sobre a peça. 
Uma particularidade do capítulo 10 que fala sobre a comunicação do ator é o emprego da palavra irradiação. Esta palavra é utilizada de forma provisória por Stanislávski para designar a comunicação sem palavras, por um caminho invisível, como uma transmissão de raios.

Neste ponto pode-se inferir novamente que ele conhecia e utilizava toda a discussão instaurada pela psicologia, pois como aponta Saura o termo "irradiação" foi tomado por Stanislávski do livro Psicologia da atenção de Ribot. (SAURA Apud STANISLÁVSKI, 2010, p.268) A irradiação seria utilizada no sentido de afinar a atenção e a sensibilidade do intérprete para melhorar seu desempenho espetacular.

A questão da irradiação está diretamente ligada à questão da atenção, figura-se como mais uma das omissões/distorções de aspectos fundamentais da obra de Stanislávski feitas pela tradução de Elizabeth Hapgood. Por não parecer um elemento importante da obra de Stanislávski na tradução americana, os treinamentos de irradiação foram deixados de lado pela maioria de seus discípulos da escola americana e das por ela influenciadas.

O capítulo 11 fala mais especificamente sobre a adaptação que, nas palavras de Stanislávski (2010, p. 280), pode ser descrita como os meios internos e externos com os quais as pessoas se adaptam umas as outras para se comunicar e ajudam-se, mutuamente, a alcançaro objeto. A adaptação em cena é um recurso, uma estratégia que ajuda a atrair a atenção da pessoa com quem se deseja estar em contato.

A partir de todas essas evidências é possível concluir que trabalhar a atenção do ator, segundo a perspectiva de Stanislávski, é buscar cercar o material insondável do inconsciente a partir de seus vestígios mais epidérmicos. É conhecer mais sobre a natureza humana para poder aumentar a eficácia da comunicação que deve existir no momento da cena.

Por isso, a obra de Stanislávski sobre a preparação do ator é um ponto fundamental da retomada da discussão da atenção do ator. A partir da revisão da obra de Stanislávski (2010) percebe-se a importância e a potência que ela tem, ainda hoje, para os estudantes de teatro, em especial para os atores. Mostram-se novos horizontes para o treinamento do ator, nos quais a atenção figura-se como um elemento fundamental, tal como já ocorre nas escolas russas de teatro.

\footnotetext{
${ }^{9}$ O conceito de irradiação foi desenvolvido de forma vertical pelo aluno de Stanislávski, Michael Chekhov (2010) em seu livro "Para o Ator."
} 


\section{Referências Bibliográficas}

ANDREW, J. Dudley. As Principais Teorias do Cinema. Rio de Janeiro: Jorge Zahar Editor, 1989.

CARNEIRO, Leonel Martins. A atenção e a cena. 2011. 203 páginas. Dissertação de Mestrado em Artes Cênicas. ECA/USP, São Paulo, 2011.

CHEKOV, Michael. Para o Ator. São Paulo: Martins Fontes, 2010.

CRAIG, E. Gordon. Da arte do Teatro. Lisboa: Escola Superior de Teatro e Cinema de Lisboa, 2004.

CRARY, Jonathan. A visão que se desprende: Manet e o observador atento no fim do século XIX. In: CHARNEY, Leo; SCHWARTZ, Vanessa R. (Org.). O cinema e a invenção da vida moderna. São Paulo: Cosac \& Naify, 2001, p. 67-94.

Suspensions of perception: attention, spectacle, and modern culture. Massachusetts/ London: MIT Press, 1999.

DIDEROT, Denis. Discurso sobre a poesia dramática. São Paulo, Cosac Naify, 2005.

FABER, Vreneli. Stanislávski in Practice: Actor Training in Post-Soviet Russia. New York: Peter Lang Pub., 2008.

HATFIELD, Gary. Attention in early scientific psychology. In: WRIGHT, Richard. (ed.) Visual Attention. New York: Oxford University Press, 1998.

HELENE, André F. \& XAVIER, Gilberto F. A construção da atenção a partir da memória. Revista Brasileira de Psiquiatria, São Paulo, supl. 2, n. 25, p. 12-20, SET/2003.

MUNSTERBERG, Hugo. The Film: A Psychological Study. New York: Dover Publications, 2004.

NAHAS, T. R.; XAVIER G. F. Atenção. In: BUENO, Andrade Santos. Neuropsicologia Hoje. São Paulo: Artes Médicas, 2004.

PASHLER, Harold E. The psychology of attention. Cambrige: MIT, 1999.

RIBOT, Théodule. La Psychologie de l'attention. Paris: F. Alcan, 1889.

STANISLÁVSKY, Constantin. A Preparação do Ator - Tradução Pontes de Paula Lima ( a partir da edição americana). Rio de Janeiro: Ed.Civilização Brasileira, 1984. Routledge, 1989.

An Actor Prepares - Traduzido por Elizabeth Reynolds Hapgood. Nova Yorque:

I lavoro dell'attore su se stesso - Tradução Elena Povoleto (a partir da edição russa, com a posterior revisão dos editores americanos). Roma/Bari: Editori Laterza, 2008 (20 Ed).

El trabajo del actor sobre si mismo: en el proceso creador de la vivencia - Tradução e notas Jorge Saura (a partir da versão russa). Barcelona: Alba Editorial, 2010 (3ㄹd). 